\title{
Photographic measurement of leaf angles in field crops
}

\section{Zou, Xiaochen}

2014

Zou , X, Mottus , M , Tammeorg , P , Lizarazo Torres , C, Takala , T, Pisek, J, Makela , P

, Stoddard , F L \& Pellikka , P 2014 , ' Photographic measurement of leaf angles in field crops ' , Agricultural and Forest Meteorology , vol. 184 , pp. 137-146 . https://doi.org/10.1016/j.agrformet.2013.09.01

http://hdl.handle.net/10138/44805

https://doi.org/10.1016/j.agrformet.2013.09.010

publishedVersion

Downloaded from Helda, University of Helsinki institutional repository.

This is an electronic reprint of the original article.

This reprint may differ from the original in pagination and typographic detail.

Please cite the original version. 


\title{
Photographic measurement of leaf angles in field crops
}

\author{
Xiaochen Zou ${ }^{a}, *$, Matti Mõttus ${ }^{a}$, Priit Tammeorg ${ }^{b}$, Clara Lizarazo Torres ${ }^{b}$, Tuure Takala ${ }^{a}$, \\ Jan Pisek ${ }^{\mathrm{c}}$, Pirjo Mäkelä ${ }^{\mathrm{b}}$, F.L. Stoddard ${ }^{\mathrm{b}}$, Petri Pellikka ${ }^{\mathrm{a}}$ \\ a Department of Geosciences and Geography, P.O. Box 64, FI-00014 University of Helsinki, Finland \\ ${ }^{\mathrm{b}}$ Department of Agricultural Sciences, P.O. Box 27, FI-00014 University of Helsinki, Finland \\ ${ }^{\mathrm{c}}$ Tartu Observatory, 61602 Tõravere, Tartumaa, Estonia
}

\section{A R T I C L E I N F O}

\section{Article history:}

Received 23 May 2013

Received in revised form 2 September 2013

Accepted 11 September 2013

\section{Keywords:}

Leaf angle distribution

Digital camera

Field crops

Spectral reflectance

\begin{abstract}
A B S T R A C T
Leaf angle distribution (LAD) is one of the most important parameters used to describe the structure of horizontally homogeneous vegetation canopies such as field crops. LAD affects how incident photosynthetically active radiation is distributed on plant leaves, thus directly affecting plant productivity. Knowledge of LAD is also required for retrieval of other important biophysical variables from measurements of canopy radiation transmittance or spectral reflectance. Unfortunately, its determination is laborious and measured data is rarely available. In this study, we applied a recently developed method for determination of the inclination angles using leveled digital photography to the leaves of six cool-temperate crops: faba bean, narrow-leafed lupin, turnip rape, wheat, barley, and oat. The method, previously applied only to small and flat leaves of broadleaved trees and bushes, was extended to be applicable to the narrow and curved leaves of cereals. A reasonable match was found between the leaf angles determined by photographic measurements and the mean leaf tilt angles (MTA) measured using a LAI-2000 plant canopy analyzer for five out of the six species $\left(R^{2}=0.92\right)$. The error caused by assuming a spherical LAD, when calculating LAI from canopy transmittance measurements, varied between 0 and 1.5 LAI units, depending on species. Finally, we analyzed the correlation between photographically determined species-specific LADs and airborne imaging spectroscopy data acquired for the same species in a similar growth stage. The highest correlation between spectral reflectance factor and leaf mean tilt angle was found at a wavelength of $748 \mathrm{~nm}(R=0.80)$. The high correlation between MTA and this red edge waveband can be useful for MTA determination from imaging spectroscopy.
\end{abstract}

(c) 2013 Elsevier B.V. All rights reserved.

\section{Introduction}

In field crops grown under favorable conditions, leaves of neighboring plants form a (quasi-)continuous layer, called the vegetation canopy, that captures incident photosynthetically active radiation. The radiation fluxes reflected, transmitted and absorbed by plants determine canopy albedo, the light conditions below the canopy, and the amount of energy available for photosynthesis. The mean values of canopy radiation fluxes and the irradiance distribution on leaf surfaces, determined by the spatial distribution of leaves (in other words, canopy structure) have significant effects on the photosynthetic capacity of plants (Gutschick, 1991). At the same time, canopy structure also largely determines what the canopy looks like when observed from above, for example, by a remote sensing instrument (Knyazikhin et al., 2012). This creates a problem for retrieving canopy biophysical variables (e.g., chlorophyll

\footnotetext{
* Corresponding author. Tel.: +358 0465513684.

E-mail addresses: zouxiaochen902@126.com, xiaochen.zou@helsinki.fi (X. Zou).
}

content, leaf area index) using common remote sensing algorithms (Houborg et al., 2007; Viña et al., 2011).

The amount of leaf cover in a vegetation canopy is commonly quantified using the Leaf Area Index (LAI), defined as hemisurface leaf area per unit horizontal ground area (Watson, 1947). The second most commonly used structural characteristic of a vegetation canopy is the Leaf Angle Distribution (LAD) function, which is defined as the probability of a leaf element of unit size to have its normal within a specified unit solid angle. Assuming uniform distribution of leaf azimuth angles, LAD becomes the probability density function of the zenith angle $\theta_{L}$ of leaf normal. For simple and horizontally relatively homogeneous canopies, the two quantities, LAD and LAI, are the only two structure parameters required for accurate prediction of reflected, transmitted and absorbed radiation fluxes (Ross, 1981; Lang et al., 1985).

A set of mathematical LAD functions is commonly used to classify the measured leaf angle distributions (de Wit, 1965; Weiss et al., 2004). Here, we use the planophile, spherical, and erectophile distributions in the formulation given by Weiss et al. (2004), the abstract case of a canopy of exclusively horizontal leaves (horizontal LAD), as well as a canopy with the same proportion of leaf area 
Table 1

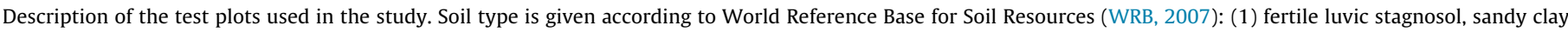
loam; (2) haplic gleysols, silty clay loam; (3) sulfic cryaquepts; and (4) fertile luvic stagnosol, sandy medium clay loam.

\begin{tabular}{|c|c|c|c|c|c|c|c|c|c|}
\hline & Faba bean & & Narrow-leafed lupin & Turnip rape & Wheat & & Barley & & Oat \\
\hline Plot size $(\mathrm{m} \times \mathrm{m})$ & $25 \times 8$ & $10 \times 2$ & $25 \times 8$ & $25 \times 8$ & $25 \times 8$ & $10 \times 2$ & $50 \times 12$ & $25 \times 8$ & $25 \times 8$ \\
\hline Number of plots & 4 & 36 & 4 & 4 & 4 & 96 & 6 & 4 & 4 \\
\hline Fertilizer application $\left(\mathrm{kg} \mathrm{N} \mathrm{ha}^{-1}\right)$ & 21 & $12-40$ & 21 & 109 & 119 & $0-150$ & $89-100$ & 99 & 99 \\
\hline Seeding density $\left(\mathrm{m}^{-2}\right)$ & 55 & 60 & 125 & 300 & 700 & 650 & $450-550$ & 600 & 500 \\
\hline Soil type & 3 & 1 & 3 & 3 & 3 & 1,2 & 4 & 3 & 3 \\
\hline
\end{tabular}

at any angle (uniform LAD). Of these distributions, the erectophile canopy has the largest mean zenith angle of leaf normal (or, equivalently, the largest Mean leaf Tilt Angle, MTA) followed in order of decreasing MTA by canopies with spherical, uniform, planophile and horizontal LADs.

Traditionally, LAD has been measured with mechanical inclinometers that have been put in a contact with leaf surfaces. This direct method is laborious and requires access to and careful measurement of a large number of leaf surfaces (Lang et al., 1985). Modern alternatives to traditional inclinometer measurements include 3D digitizing of individual plant elements using specialized instrumentation (Sinoquet et al., 1998) and laser scanning (Hosoi et al., 2009), but these approaches are resource-demanding, resulting in a lack of data on the LADs of many crops. A common approach is then to use the spherical LAD, that is, to assume that leaves have no preferred orientation (Goudriaan, 1988; Campbell and Norman, 1998; Weiss et al., 2004).

Indirect methods have been developed to retrieve the information on leaf inclination angles from measurements of radiation penetration of the canopy at different view angles (Lang, 1986). Unfortunately, it is almost impossible to differentiate the effects of leaf angles on canopy transmittance from other structural influences.

A new method has been developed, based on analyzing leveled digital camera images of canopies consisting of flat leaves (Ryu et al., 2010a; Pisek et al., 2011, 2013). This method, here called the photographic method, allows for a rapid, non-contact and accurate estimation of LAD (Ryu et al., 2010a). It has shown potential to overcome many of the shortcomings of other LAD measurement techniques. The photographic method has been applied successfully to a number of broadleaf canopies (Pisek et al., 2011, 2013).

The aim of this research was to extend the photographic LAD estimation method to field crops with long non-flat leaves that do not have any unique inclination angle. We determined the LAD of six cool-temperate crops with diverse growth habits, and compared the results of the photographic method to a well-established technique based on the angular dependence of canopy transmittance and to literature values. Finally, we tested the potential for using crop LAD and transmittance measurements to calculate LAI and the influence of LAD on the spectral reflectance in visible and near-infrared wavebands.

\section{Materials and methods}

\subsection{Study site}

The study site was part of the Viikki Experimental Farm in Helsinki, University of Helsinki, Finland $\left(60.224^{\circ} \mathrm{N}, 25.021^{\circ} \mathrm{E}\right.$, altitude $10 \mathrm{~m}$ above sea level). Six crop species, narrow-leafed lupin (Lupinus angustifolius L. 'Haags Blaue'), faba bean (Vicia faba L. 'Kontu'), turnip rape (Brassica rapa L. ssp. oleifera (DC.) Metzg. 'Apollo'), wheat (Triticum aestivum L. emend Thell. 'Amaretto'), barley (Hordeum vulgare L. 'Streif', 'Chill' and 'Fairytale') and oat (Avena sativa L. 'Ivory' and 'Mirella') were included in this study, representing three plant families and different growth habits, and widely grown throughout cool-temperate regions of the world (Table 1 ).
They were grown in four different field experiments and a single plot of each species was used for photographic determination of leaf angles in 2012. The values were considered to be typical to each species, i.e., we assumed crop LAD to be a species-specific parameter (Ross, 1981; Campbell, 1990; Campbell and Norman, 1998; Weiss et al., 2004). Spectroscopic information on a set of 162 plots of these species had been obtained one year before photographic measurements, in 2011 in the same crop development stage. The number of plots of each species as well as the sizes of the plots for which spectral data was available varied between treatments, soil type and species (Table 1 ). The row spacing for all crops was $12.5 \mathrm{~cm}$ and the canopy height was less than $1 \mathrm{~m}$. Although three barley and two oat cultivars were used in 2011, variation between cultivars was small in comparison to that between species, and cultivar datasets were pooled.

\subsection{Airborne imaging spectroscopy data}

Imaging spectroscopy data was acquired on July 25, 2011, with the AISA Eagle II airborne imaging spectrometer (Specim Ltd., Oulu, Finland) onboard a twin-engine Piper PA-23 aircraft at a flying height of approximately $600 \mathrm{~m}$. Measurements were carried out between 09:36 and 10:00 local time, when solar zenith angle varied between $50.4^{\circ}$ and $48.1^{\circ}$. For each pixel, the measurement zenith angle was between zero and half of the sensor field of view (i.e., $0-18.9^{\circ}$ ) and the sensor azimuth angle measured relative to the solar direction was approximately $90^{\circ}$.

Reflected radiation was measured in 64 channels spanning the visible and near-infrared parts of the solar spectrum $(400-1000 \mathrm{~nm})$ with a spectral resolution of $9-10 \mathrm{~nm}$, and a spatial resolution of $0.4 \mathrm{~m}$. The spectroscopic image was radiometrically calibrated using the CaliGeo software package (Specim Ltd., Oulu, Finland). Next, the data were georectifed using Parge (ReSe Applications Schläpfer, Wil, Switzerland) with the help of ground control points and the inertial navigation data recorded during the flight. Finally, the data were calculated to below-atmosphere hemispherical-directional reflectance factors using ATCOR-4 (ReSe Applications Schläpfer, Wil, Switzerland).

We extracted the spectral data corresponding to the 162 test plots and calculated the average reflectance spectrum for each plot. Finally, to cope with the large imbalance in the data set dominated by wheat and faba bean, we grouped the measurements by LAI values and calculated the averaged spectrum for each species and unit LAI interval (Table 2). The grouped dataset consisted of 18 averaged spectra. However, for some analyses, the distribution of plots between species was non-significant and we treated the average spectrum of each of the 162 plots as a separate measurement.

\subsection{Leaf area index measurement}

The SunScan SS1 ceptometer bar (Delta-T Devices, Cambridge, UK) canopy analysis system was used to measure the LAI of the 162 test plots weekly in July 2011. By choosing the data with the date closest to the airborne campaign, the LAI data used in our analyses was collected within five days of the airborne data acquisition. SunScan was entered from one edge of the plot at about $45^{\circ}$ to the 
Table 2

Number of plots measured with airborne imaging spectrometer for each species and LAI interval.

\begin{tabular}{lccrrr}
\hline \multirow{2}{*}{ Species } & \multicolumn{2}{l}{ LAI level } & & & \\
\cline { 2 - 6 } & $1-2$ & $2-3$ & $3-4$ & $4-5$ & $5-6$ \\
\hline Faba bean & - & - & 10 & 26 & 4 \\
Narrow-leafed lupin & - & - & - & 2 & 2 \\
Turnip rape & - & - & 1 & 1 & 2 \\
Wheat & 18 & 32 & 26 & 21 & 3 \\
Barley & - & 1 & 2 & 4 & 3 \\
Oat & - & - & 4 & - & - \\
\hline
\end{tabular}

crop row direction in order to minimize row effects on LAI readings. The sampling scheme was designed to account for the small sizes of some of the plots. Measurements were always taken sufficiently far from the plot edge that the radiation reaching the sensor always entered the canopy through its top surface. The LAI value from each plot was the mean of 4-5 sequential SunScan readings.

The SunScan instrument, consisting of 64 miniature sensors aligned on a one-meter rod, is used to measure downwelling photosynthetically active radiation above and below the canopy. A separate sensor measures the ratio of direct to diffuse downwelling irradiance. LAI is calculated from radiation measurements assuming an exponential extinction of radiation (i.e., the Beer-Lambert law) and a predetermined leaf angle distribution. Solar elevation is calculated from geographical coordinates and local time. Based on these data and the Beer-Lambert law of exponential attenuation of radiation, the instrument calculates the LAI of the canopy using an algorithm implemented in its hardware. The full details of the computations are given in the manual of the instrument (SunScan SS1 user manual version 2.0).

For a correct interpretation of the radiation transmittance measurements, the algorithm requires a priori information on the distribution of leaf inclination angles. In the LAI calculation algorithm, this distribution is quantified using the single parameter $\chi$ of the ellipsoidal leaf angle distribution (LAD) model proposed by Campbell (1986). Although some species-specific values measured by Campbell and Norman (1998) are suggested in the manual, a common practice is to assume $\chi=1$ corresponding to spherical distribution of leaf normals (Goudriaan, 1988; Weiss et al., 2004) (i.e., leaves have no preferred orientation), as no reliable information on the actual leaf angles is usually available. The size of the error caused by assuming a wrong LAD depends on LAI, illumination conditions (i.e., solar angle and the fraction of diffuse sky radiation), and the actual LAD of the canopy (Ross, 1981; Lang et al., 1985).

As no information on actual leaf angles was available to us during the measurements, we assumed a spherical distribution of leaf normals $(\chi=1)$. Later, we reanalyzed the SunScan-measured irradiances above and below the crop canopies with the same equations implemented in SunScan hardware to obtain more accurate LAI estimates and to quantify the errors caused by misrepresenting the crop LAD. The required ellipsoidal distribution parameter $\chi$ was calculated from MTA after solving Eq. (16) in Campbell (1990) for $\chi$

$\chi=-3+\left(\frac{M T A}{9.65}\right)^{-0.6061}$

The MTA values measured both by LAI-2000 (Section 2.5) and the photographic method were used to calculate more accurate LAI estimates from the SunScan transmittance data. The difference between the original $(\chi=1)$ and corrected ( $\chi$ from either LAI-2000 or photographic LAD measurement) was quantified using the Root Mean Square Difference (RMSD) and mean bias of LAI.

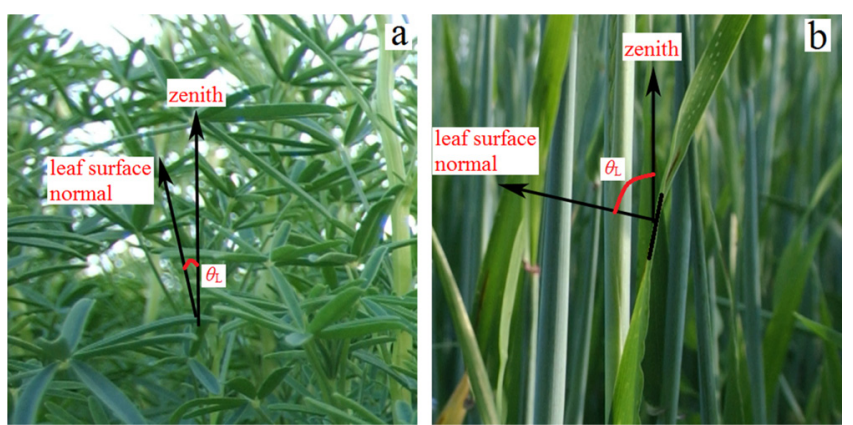

Fig. 1. Measurement of leaf inclination angle: (a) flat leaf and (b) long and curved cereal leaf.

\subsection{Photographic measurement of leaf angles}

The species-specific leaf angle distribution for the six crops was determined using a Nikon D1X digital camera (Nikon Corporation, Tokyo, Japan) approximately one year after the airborne campaign, on July 6, 2012. Photographs were taken with the camera fixed on a tripod and leveled using a bubble level in the flash shoe. The camera was placed outside the plots at a distance of about $1 \mathrm{~m}$ from the plot edge. The camera height was between 30 and $50 \mathrm{~cm}$, depending on crop height. The barley and oat plots were surrounded by natural grasses that had to be cut to obtain an unobstructed view of the crops. The natural grasses were of approximately the same height as the crops and formed a continuous canopy. The plots of other species were surrounded by strips of bare soil. Five to six photographs were taken of each species growing in one or several plots.

The leaves of the three dicotyledonous crops (narrow-leafed lupin, faba bean and turnip rape) are flat and attached to the stem via a petiole. The inclination angles of the leaves of these species were determined from photographs using the Image J software (http://rsb.info.nih.gov/ij/) following the standard approach for photographic measurement of leaf angles (Pisek et al., 2011): from the images, we selected 75-100 leaves oriented perpendicularly to the viewing direction and measured the angle between the zenith and the leaf surface normal (Fig. 1a). Assuming a uniform distribution of leaf azimuth angles, the measured inclination angle distribution is representative for all leaves, not only the ones perpendicular to viewing direction. In addition to uniform leaf azimuth distribution, the photographic method is based on the assumption of independence of the size of a leaf and its inclination angle. Accounting for a correlation between these two variables requires a simultaneous recording of the size of each leaf. However, for flat leaves similar to those of the three species discussed here, the consideration of leaf size has been found unnecessary (Ryu et al., 2010a; Pisek et al., 2011).

The leaves of the three cereal crops (wheat, barley and oat) are long, narrow and curved. No single leaf angle value can be associated with these leaves, so their inclination angles cannot be measured from the image directly. Hence, we visually divided the leaves in the images into measurable segments and measured the inclination angles of the segments that were perpendicular to the view direction (Fig. 1b). Furthermore, as leaves can bend under their own weight, the areas of segments and their inclination angles cannot be assumed to be independent, so we recorded the relative lengths and locations of the segments in the photographs.

To convert the relative length coordinates into (relative) leaf areas, we scanned 20 leaves of each species with a portable document scanner. The leaves were divided into 10 segments of equal length and a fourth order polynomial was fitted as the leaf shape function, with which we calculated the relative (with respect to the 
total area of the leaf) area of each measured segment. The relative areas were later used as weights in calculating LAD.

\subsection{Plant canopy analyzer measurements}

LAI-2000 plant canopy analyzer (Li-Cor, Lincoln, USA) measurements were made on July 5-6, 2012, in plots of all six studied species, including the plots used for photographic measurement of leaf angles. In this study, LAI-2000 was adopted in order to estimate MTA values that were compared with the leaf angles obtained photographically. LAI-2000 measures downwelling radiation in five concentric rings. Measurements made above and below a vegetation canopy are used to calculate canopy transmittance. Next, the dependence of canopy transmittance as a function of view zenith angle is used to estimate the G-function (see Section 2.7). Finally, MTA is calculated after Lang (1986), using an empirical polynomial relating leaf inclination angle to the slope of the G-function between $25^{\circ}$ and $65^{\circ}$.

LAI-2000 measurements were made during $2 \mathrm{~h}$ before sunset to avoid direct solar radiation in any of the rings of the instrument. To exclude the observer, minimize edge effects and guarantee that the radiation reaching the sensor always entered the canopy through its top surface, a $180^{\circ}$ view restricting cap was used. The same sensor was used to record both below- and above-canopy readings. The measurements were taken along the edges of the plots and we avoided the situation that the sunlight traveled parallel to the row to exclude the row effect. Depending on plot size, 4-10 belowcanopy measurements were used to calculate the average MTA. The MTA values were computed with the FV2000 software downloaded from the website of instrument manufacturer.

\subsection{Fitting the leaf inclination angle distribution}

For leaves with a uniform distribution of azimuth angle, the LAD is fully described by the distribution of the leaf inclination angle. As demonstrated by Wang et al. (2007), natural leaf angle distributions can be fitted reasonably well by the two-parameter beta distribution (Goel and Strebel, 1984). The beta distribution has also been adopted in recent research on the photographic method for measuring LAD (e.g., Pisek et al., 2011, 2013). Thus, the distribution of the leaf inclination angle $\theta_{L}$ is quantified with the density function

$f(t)=\frac{1}{B(\mu, \nu)}(1-t)^{\mu-1} t^{\nu-1}$,

where $t=2 \theta_{L} / \pi, \theta_{L}$ is the leaf inclination angle (or, the zenith angle of leaf normal), and $B(\mu, v)$ is the beta function. The two parameters $\mu$ and $\nu$ are calculated as

$\mu=(1-\bar{t})\left(\frac{\sigma_{o}^{2}}{\sigma_{t}^{2}}-1\right)$,

$v=\bar{t}\left(\frac{\sigma_{0}^{2}}{\sigma_{t}^{2}}-1\right)$,

where $\bar{t}$ and $\sigma_{t}^{2}$ are the mean value and variance of $t$, respectively, and $\sigma_{0}^{2}$ is the maximum variance of $t$ calculated as

$\sigma_{0}^{2}=\bar{t}(1-\bar{t})$.

As described in Section 2.5, the statistical characteristics of the leaf angle distribution of the curved leaves of cereals were calculated using the relative areas of the leaf segments as weights. Thus, for these species, $\bar{t}$ and $\sigma_{t}^{2}$ are the weighted mean and variance of $t$, respectively. To evaluate the size of the effect of weighting, we also used the non-weighted $\bar{t}$ and $\sigma_{t}^{2}$ to fit the beta distribution function. Finally, we analyzed the relationships of the leaf angle

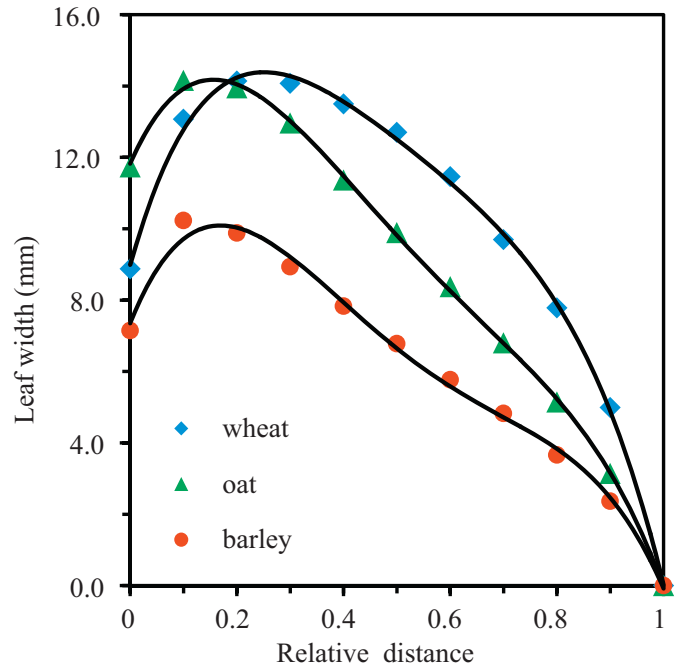

Fig. 2. The measured average leaf shape functions for wheat, barley and oat fitted by fourth order polynomials. The relative coordinate ( $x$-axis) ranging from 0 to 1 is measured from leaf insertion point. The fitted functions are $y=-100.1 x^{4}+$ $210.2 x^{3}-172.1 x^{2}+53.0 x+9.0$ for wheat, $y=-85.7 x^{4}+189.1 x^{3}-149.4 x^{2}+34.1 x$ +11.8 for oat, $y=-95.0 x^{4}+208.1 x^{3}-157.9 x^{2}+37.4 x+7.3$ for barley.

statistics with both of the beta distribution parameters $\mu$ and $v$ to identify opportunities for making the assessment and modeling of leaf angle distribution quicker and easier.

\section{G-function}

The effect of leaf inclination angles on radiation attenuation can be described using the Ross-Nilson G-function (Ross and Nilson, 1965), defined as the average projection of unit leaf area in the view direction. Under the assumption of uniform distribution of leaf azimuth angles, the projected area (i.e., the $\mathrm{G}$-function) can be expressed as (Warren Wilson, 1967):

$G(\theta)=\int_{0}^{\pi / 2} A\left(\theta, \theta_{L}\right) f\left(\theta_{L}\right) d \theta_{L}$

$A\left(\theta, \theta_{L}\right)= \begin{cases}\cos \theta \cos \theta_{L}, & \text { if }\left|\cot \theta \cot \theta_{L}\right|>1 \\ \cos \theta \cos \theta_{L}\left[1+\frac{2}{\pi}(\tan \psi-\psi)\right], & \text { otherwise, }\end{cases}$

where $\theta$ is the view zenith angle, $\theta_{L}$ is the leaf inclination angle, and

$\psi=\cos ^{-1}\left(\cot \theta \cot \theta_{L}\right)$.

Similarly to Pisek et al. (2011), we calculated $G(\theta)$ from the beta distribution fitted to actual measurements, i.e., used the beta distribution function as the function $f\left(\theta_{L}\right)$ in Eq. (6).

\section{Results}

The leaves of the three cereal crops used in the study (wheat, barley and oat) had similar shapes (Fig. 2). Moving along leaf midrib from the attachment point (relative coordinate 0 ), the width of the leaves increased somewhat with the maximum reached at relative coordinate values less than 0.2 . After reaching the maximum, leaf width decreased monotonously up to the leaf tip (relative coordinate 1 ). The leaf shape functions could be fitted well with the fourth order polynomial function.

Faba bean, narrow-leafed lupin and turnip rape (Fig. 3a-c, respectively) showed a more horizontal LAD than the cereal crops, with their long and narrow leaves (Fig. 3d-f). Disregarding the noise 

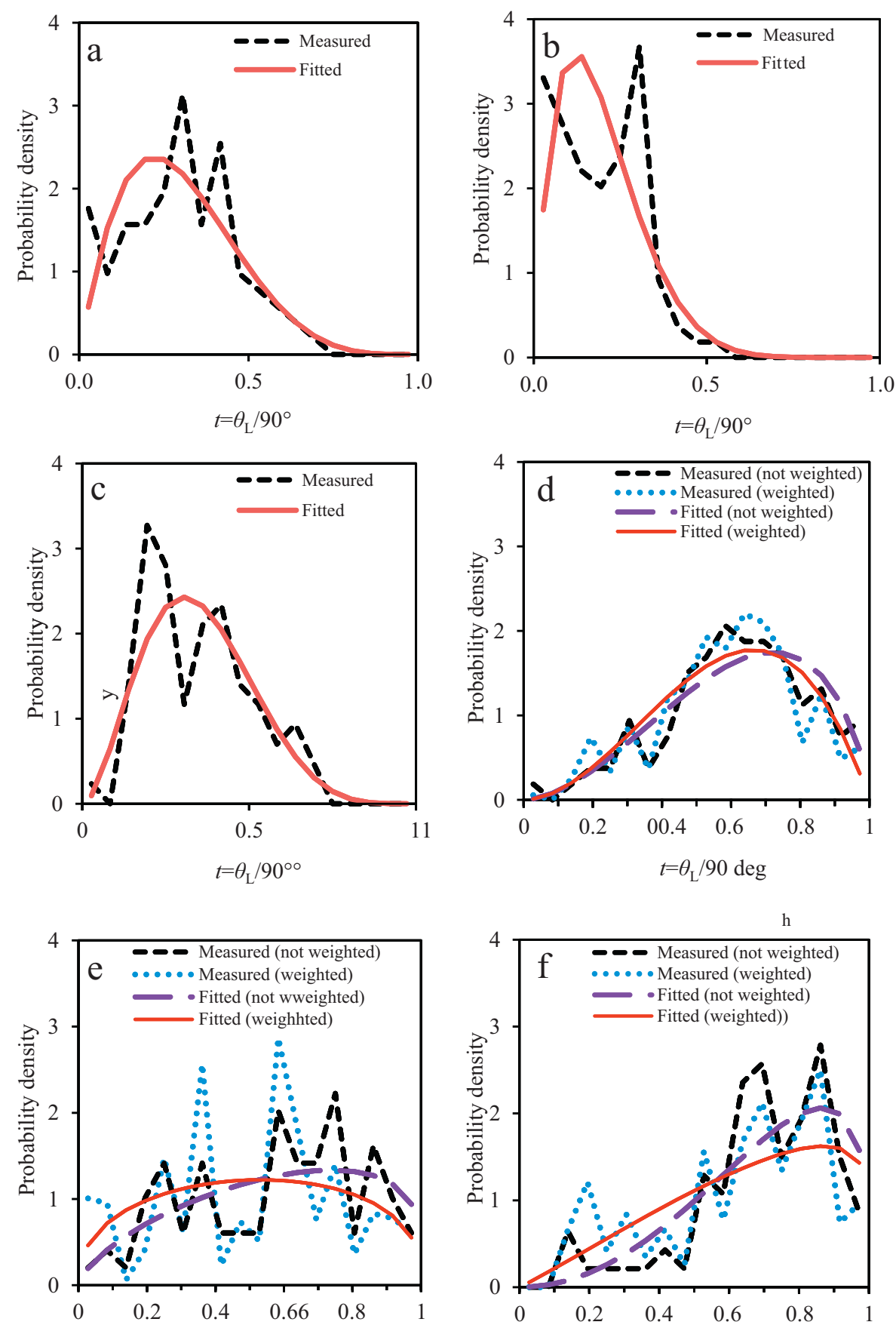

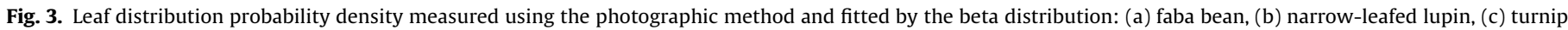
rape, (d) wheat, (e) barley, and (f) oat. The leaf inclination angle $\theta_{L}$ is measured from horizontal $\left(\theta_{L}=90^{\circ}\right.$ indicates a vertical leaf).

Table 3

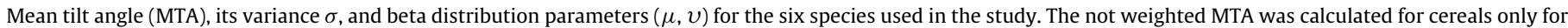
illustrative purposes and was not used for calculating $\sigma, \mu$, and $v$.

\begin{tabular}{|c|c|c|c|c|c|}
\hline Species & MTA $\left({ }^{\circ}\right)$ not weighted & MTA $\left({ }^{\circ}\right)$ weighted & $\sigma\left(^{\circ}\right)$ & $\mu$ & $v$ \\
\hline Faba bean & 27.1 & - & 14.6 & 4.88 & 2.10 \\
\hline Narrow-leafed lupin & 17.6 & - & 10.7 & 8.12 & 1.98 \\
\hline Turnip rape & 31.6 & - & 13.9 & 5.51 & 2.99 \\
\hline Wheat & 56.1 & 53.9 & 18.0 & 2.01 & 3.00 \\
\hline Barley & 51.8 & 45.8 & 23.1 & 1.37 & 1.42 \\
\hline Oat & 63.2 & 57.8 & 20.9 & 1.16 & 2.08 \\
\hline
\end{tabular}


in the measured distribution function caused by the small sample sizes, the beta-function reproduced the measured distributions reasonably well. The effect of weighting is evident in Fig. 3d-f: weighting shifted the maximum of the LAD toward smaller leaf inclination angle values, but the differences were rather small, especially for wheat (Fig. 3d). Based on our measurements, weighting the measured leaf inclination angles of cereal crops by the relative areas of leaf segments can alter $\theta_{L}$ by as much as six degrees (Table 3 ). In our dataset, the values of $\mu$ varied between 1 and 8 while the range of $v$ was between 1 and 3 (Table 3 ). A strong and negative linear correlation existed between MTA and $\mu$ (Fig. 4, $\left.R^{2}=0.90\right)$ while $v$ was not correlated with mean leaf inclination angle $\left(R^{2}=0.01\right)$

The differences between the LADs of the cereals and other crops were also clearly visible when their G-functions were plotted as functions of view angles (Fig. 5a). The G-function of faba bean made an excellent fit to the theoretical planophile LAD. The leaves of turnip rape were slightly more vertical than those of faba bean, and leaves of narrow-leafed lupin were close to horizontal. The $\mathrm{G}$-function for barley, among the cereal crops, was closest to that of the uniform LAD. For oat, the G-function was indistinguishable from the spherical one $\left(G\left(\theta_{L}\right) \equiv 0.5\right)$, and the $G$-function for wheat was between those of the two other cereals. The G-functions in Fig. 5a were calculated with the weighted $\bar{t}$ and $\sigma_{t}^{2}$, taking into account the correlation between leaf segment size and its inclination angle. Weighting had a considerable effect on the G-function. Indeed, without weighting, the G-function of oat resembled that of an erectophile canopy (Fig. 5b), but after weighting, it became independent of view angle $\left(G\left(\theta_{L}\right) \equiv 0.5\right)$. Similarly, weighting affected the $\mathrm{G}$-functions of the two other cereal crops.

The MTAs of five species (excluding narrow-leafed lupin) acquired by the two approaches, LAI-2000 and photographic measurement, showed a strong correlation $\left(R^{2}=0.92\right)$, but including narrow-leafed lupin reduced the correlation to non-significance $\left(R^{2}=0.29\right)$. The MTA measured by the LAI- 2000 was systematically larger (leaves seemed to be more vertical) than that determined using the photographic method. Generally, the difference was the largest for crops with more horizontal leaves (smaller MTA). The highest difference in MTA estimates produced by the two methods was for the outlier, narrow-leafed lupin, with a photographically determined MTA of $18^{\circ}$, and an LAI-2000-determined value of $62^{\circ}$.

The correlation coefficient $R$ between MTA and spectral reflectance factor varied from 0 to 0.80 . The lowest vales were obtained for red wavelengths (around $680 \mathrm{~nm}$ ), and the correlation was at its highest in the red edge and near infrared. As expected, the correlation was stronger when narrow-leafed lupin was excluded from the dataset. However, even with all data included, the correlation coefficient between the photographically measured MTA and spectral reflectance reached 0.80 at $748 \mathrm{~nm}$ (Fig. 7). The dependence of crop reflectance on MTA was negative: canopies with more vertical leaves had a smaller reflectance at $748 \mathrm{~nm}$.

Use of species-specific MTA, via the parameter $\chi$ of the ellipsoidal LAD model (Table 4), had a variable effect on the LAI values calculated from SunScan transmittance measurements (Fig. 9, Table 5). While the corrected and uncorrected values were highly correlated $\left(R^{2} \geq 0.98\right)$, the regression coefficient (slope of the linear regression fitted to corrected vs. uncorrected data) varied between 0.66 and 1.27 , depending on species (Table 5). The regression coefficient for the photographic method never exceeded unity: according to this technique, none of the measured species had more vertical leaves than the spherical LAD. The LAI-2000, on the other hand, indicated that cereals had LADs with predominantly vertical leaves. The RMSD in LAI units varied between 0 and 1.5 , with the highest values from the most horizontal leaves measured with the photographic technique.

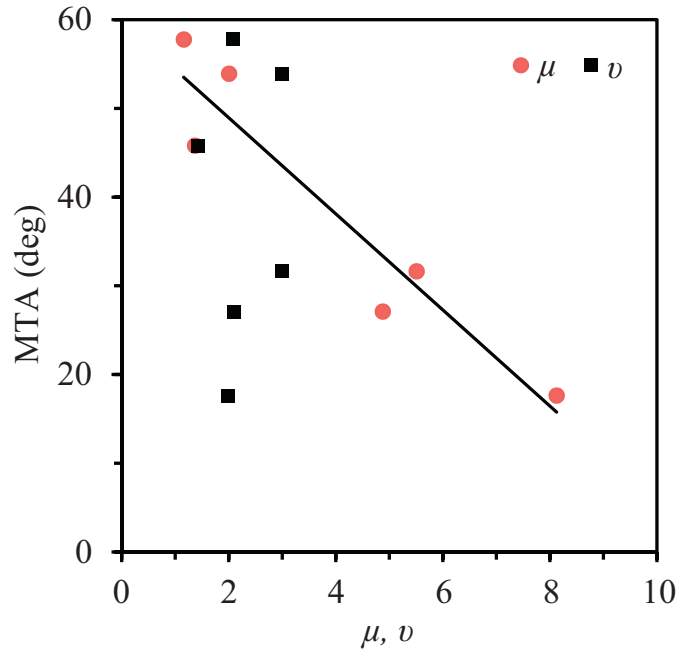

Fig. 4. The mean tilt angle (MTA) as a function of the two beta distribution parameters $\mu$ and $v$. A linear function is fitted between $\mu$ and MTA: MTA $=-5.42 \mu+59.79$ $R^{2}=0.90$. The $R^{2}$ between $v$ and MTA is 0.01 .

\section{Discussion}

Typically, crop LAD is considered species-specific (Ross, 1981; Campbell, 1990; Campbell and Norman, 1998; Weiss et al., 2004) as it tends to vary more between species (Houborg et al., 2007) than between cultivars. Furthermore, there was no significant correlation between leaf angle and time of day (i.e., solar zenith angle) for the species studied here (data not shown). Thus, we were able to combine measurements made on different years for cultivars in similar development stages. This assumption is validated by the general agreement of measured LAD (and more specifically, MTA) with the available data in the literature. The most extensive review of published leaf angle data for five of the species used in this study was given by Ross (1981), but we found no information on previous measurements of turnip rape LAD and only one mention of narrow-leafed lupin.

The MTA of faba beans growing in Estonia was between $33^{\circ}$ and 36 (Ross and Nilson, 1968; Mägi and Ross, 1969, quoted by Ross, 1981; unknown quotation in Ross, 1981). These values somewhat exceed our measured result of $27^{\circ}$ (Table 3 ) and are slightly lower than the $37-44^{\circ}$ obtained from the $\chi$-values given by Campbell and Norman (1998; Table 4). For the MTA of narrow-leafed lupin, Scott and Wells (1969) obtained $17^{\circ}$ in upper canopy layers and $30-40^{\circ}$ in lower layers, which is in agreement with our canopy-average value of $18^{\circ}$. Varying values for the inclination angles of barley are available in the literature: $41^{\circ}$ was the average MTA value for different years and development stages measured in Estonia (Mägi and Ross, 1969, quoted by Ross, 1981); 25-35 ${ }^{\circ}$ was reported by Abashina and Gorbachev (1977, quoted by Ross, 1981) during the growing season in the Kaluga region of Russia with no apparent temporal trend;

Table 4

The ellipsoidal leaf angle distribution parameter $\chi$ calculated from LAI-2000 output and the photographic method. The $\chi$ values from the SunScan manual (originally reported by Campbell and Norman, 1998) are given as reference.

\begin{tabular}{llll}
\hline \multirow{2}{*}{ Species } & \multicolumn{2}{l}{ Method } & \\
\cline { 2 - 4 } & LAI-2000 & Photographic & Reference \\
\hline Faba bean & 1.52 & 3.22 & $1.81-2.17$ \\
Narrow-leafed lupin & 0.79 & 5.07 & - \\
Turnip rape & 1.10 & 2.66 & - \\
Wheat & 0.79 & 1.10 & 0.96 \\
Barley & 0.91 & 1.53 & 1.20 \\
Oat & 0.62 & 0.93 & - \\
\hline
\end{tabular}




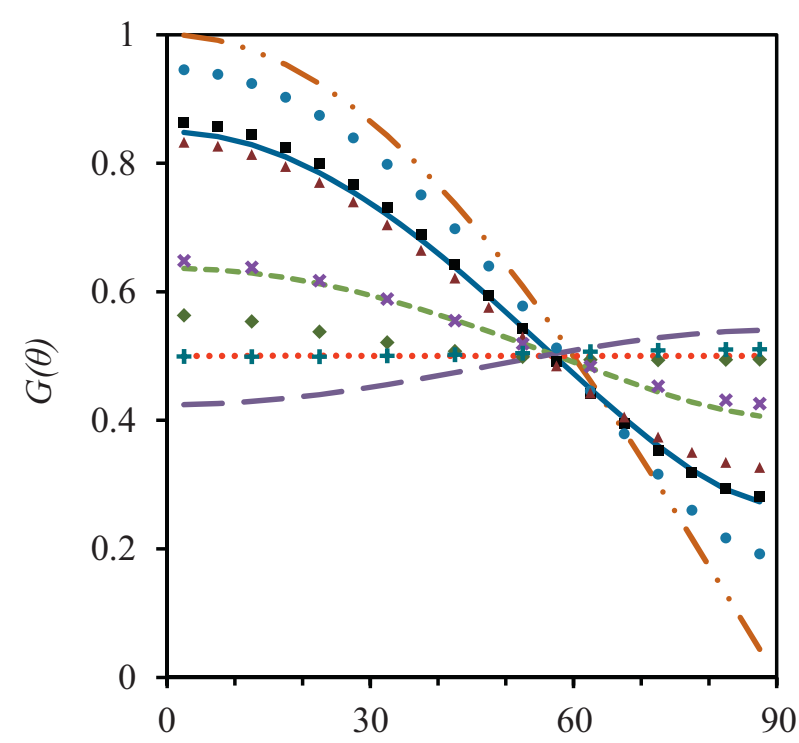

a

- Faba bean

- Narrow-leafed lupin

- Turnip rape

- Wheat

$\times \quad$ Barley

+ Oat

—.. Horizontal

Planophile

- - - Uniform

....... Spherical

— Erectophile

View zenith angle $\theta$ (deg)

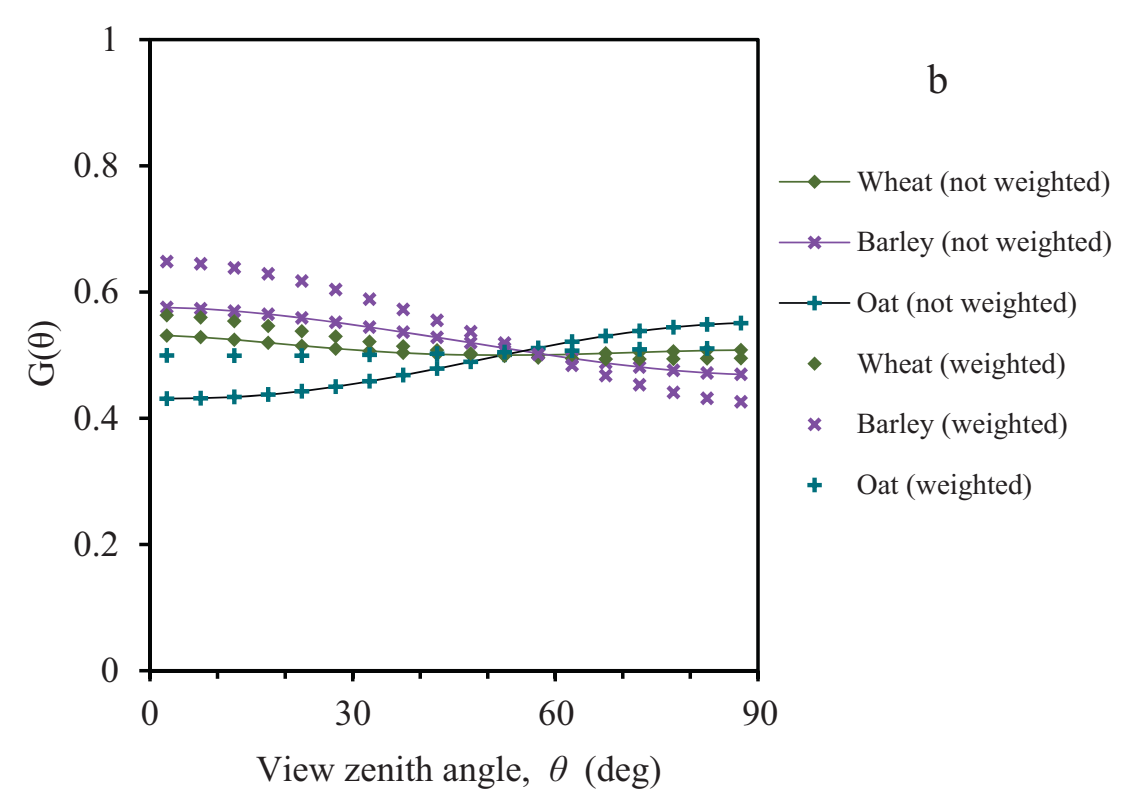

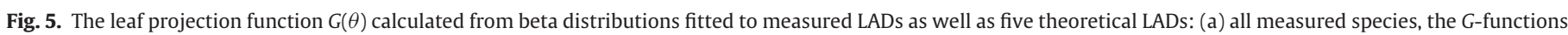

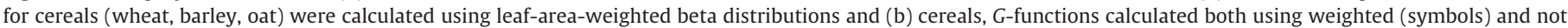
weighted (lines) beta distributions.

Table 5

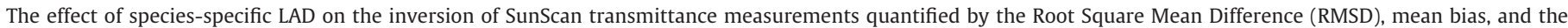

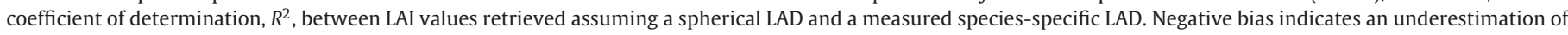
LAI when using the spherical LAD. Slope and intercept describe the corresponding linear model LAI (measured LAD) $=f(\mathrm{LAI}(\mathrm{spherical}$ LAD)).

\begin{tabular}{|c|c|c|c|c|c|c|c|c|c|c|}
\hline \multirow[t]{2}{*}{ Species } & \multicolumn{5}{|c|}{ LAI-2000 } & \multicolumn{5}{|c|}{ Photographic measurement } \\
\hline & RMSD & Bias & $R^{2}$ & Slope & Intercept & RMSD & Bias & $R^{2}$ & Slope & Intercept \\
\hline Faba bean & 0.60 & 0.59 & 1.00 & 0.81 & 0.23 & 1.10 & 1.08 & 1.00 & 0.67 & 0.32 \\
\hline Narrow-leafed lupin & 0.50 & -0.49 & 0.99 & 1.27 & -0.81 & 1.45 & 1.45 & 1.00 & 0.66 & 0.23 \\
\hline Turnip rape & 0.19 & 0.18 & 1.00 & 0.95 & 0.08 & 1.21 & 1.18 & 1.00 & 0.71 & 0.22 \\
\hline Wheat & 0.30 & -0.27 & 1.00 & 1.13 & -0.12 & 0.12 & 0.10 & 1.00 & 0.96 & 0.03 \\
\hline Barley & 0.19 & -0.18 & 1.00 & 1.06 & -0.10 & 0.63 & 0.61 & 1.00 & 0.82 & 0.19 \\
\hline Oat & 0.68 & -0.68 & 0.98 & 1.26 & -0.33 & 0.10 & 0.10 & 1.00 & 1.00 & 0.10 \\
\hline
\end{tabular}


and according to Scott and Wells (1969), MTA increased from $44^{\circ}$ in the topmost canopy layer to $53^{\circ}$ at the bottom of the canopy. The MTA calculated from the elliptical distribution parameter value reported by Campbell and Norman (1998, see also Table 4) is 52. The MTA value of $46^{\circ}$ measured by us was between these values, but the difference is not large. Wheat MTA was reported to vary from $46^{\circ}$ to $48^{\circ}$ during plant development in Colorado, U.S. (Goel and Strebel, 1984), and a value of $43^{\circ}$ was measured for wheat growing in the Moscow region (Nichiporovich, 1961, quoted by Ross, 1981). The two values are markedly different from our result of $54^{\circ}$, but the $\chi$-value in Table 3 by Campbell and Norman (1998) yields $\mathrm{MTA}=57^{\circ}$. Additionally, Huang et al. (2006) reported that winter wheat cultivars showed a huge variation in LAD, from planophile to erectophile. Erect leaves have been favored in wheat breeding as the trait is under simple genetic control and contributes to yield (Reynolds et al., 2000). Thus, at least for this species, the different results may reflect genetic variation.

All our measurements are valid for a specific growth stage only. Different authors have reported variation of MTA with growth stage (de Wit, 1965; Ross, 1981; Goel and Strebel, 1984; Huang et al., 2006; Hosoi et al., 2009), but no apparent, universal and strong trends are visible in the data. Furthermore, LAD is known to vary systematically and significantly with height in a plant stand (Scott and Wells, 1969; Ross, 1981). The photographic method enables measurement of this variation. Nevertheless, within-stand variations are difficult to incorporate into transmittance and a single average LAD is sufficient for numerous applications.

Weighting of the lengths of cereal leaf segments (as measured in a photograph) by their relative areas had a noticeable effect on both LAD (Fig. 3d-f) and G-function (Fig. 5b). In the dataset, the impact of the weighting on LAI retrieval from SunScan measurements was less than 0.4 (LAI units, both RMSD and mean bias).

The applicability of the species-specific (or, potentially, cultivarspecific) LAD is supported by strong correlations between photographic and LAI-2000 measurements (Fig. 6), and between MTA and spectral reflectance (Figs. 7 and 8). For narrow-leafed lupin, however, the MTA measured by LAI-2000 (62 ${ }^{\circ}$ ) was drastically different from that obtained by the photographic method $\left(18^{\circ}\right)$. It should be noted that the LAD output by the plant canopy analyzer is "effective", i.e., that fitting best the measured angular distribution of transmittance. The influence of canopy structural

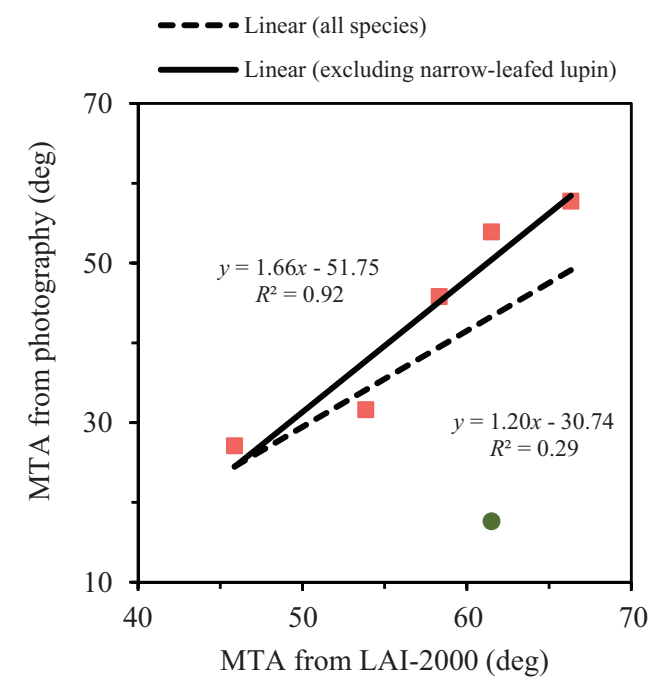

Fig. 6. The correlation between the species-specific mean tilt angle (MTA) determined using the photographic method and using the LAI-2000. A potential outlier, narrow-leafed lupin, is plotted with a filled circle. Correlation coefficients and regression lines are given separately for all six species and for a subset excluding narrow-leafed lupin.

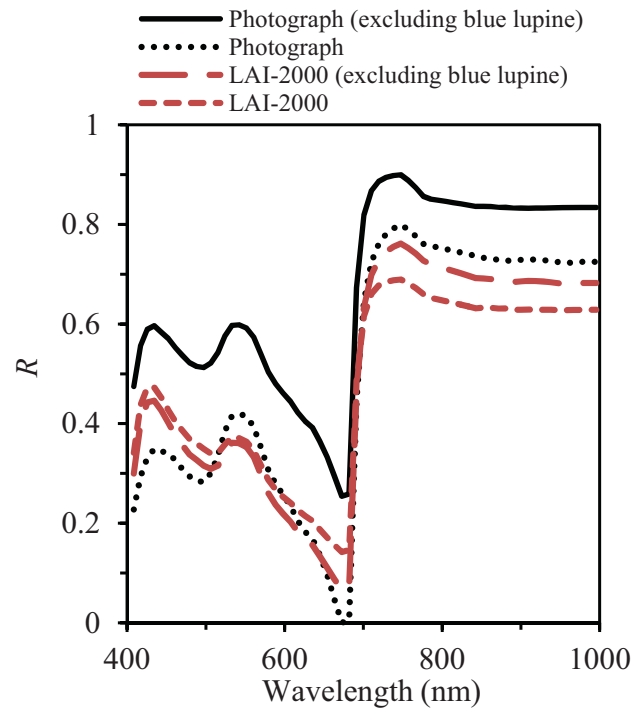

Fig. 7. The spectral dependence of the coefficient of variation $(R)$ between spectral reflectance factor and MTA measured by both photographic method and LAI-2000.

characteristics other than LAD is ignored, the canopy is assumed to be horizontally homogeneous, and the azimuth and zenith angles of leaves are considered to be independent. In reality, the narrowleafed lupin canopies in Viikki had a clear structure (Fig. 10). Narrow-leafed lupin has palmately compound leaves attached with long petioles to nearly vertical stems. Thus, although individual leaflets may have a predominantly horizontal orientation as determined from the photographs, the regular distribution of leaflets in leaves and leaves along stems may lead to a violation of the Beer-Lambert law of radiation attenuation, an underlying assumption in optical LAD retrieval algorithms. Furthermore, the leaves of several lupin species have been reported to be heliotropic, i.e., they follow the course of the sun (Scott and Wells, 1969; Ehleringer and Forseth, 1989). Heliotropism can violate the underlying assumption of isotropic distribution of leaf azimuth angles, and the independence of the azimuth and zenith angles of leaf normal.

The systematically lower MTA values measured using the photographic method, compared with the output of LAI-2000 $\left(\right.$ RMSE $=23^{\circ}$, bias $=-19^{\circ}$ ), can further be mainly explained by contribution of leaf elements other than leaves. Indeed, even if all

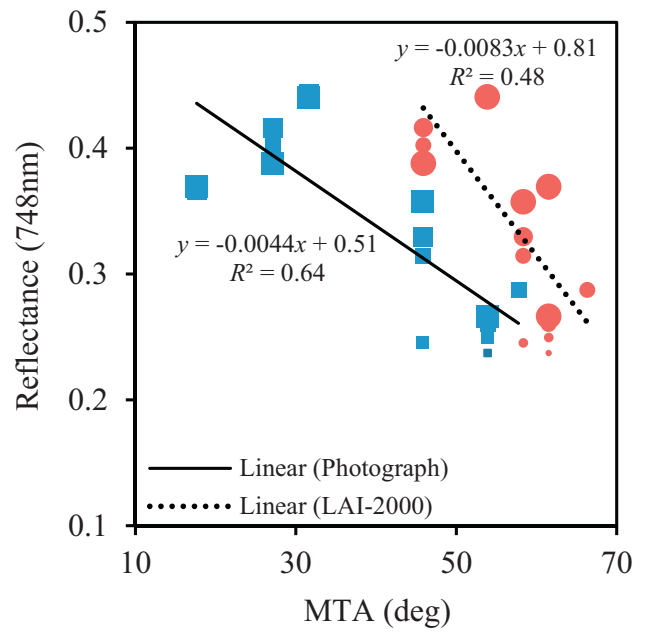

Fig. 8. The spectral reflectance factor at $748 \mathrm{~nm}$ plotted against mean tilt angles (MTA) measured by photographic method (square) and LAI-2000 (circle). The species-specific MTA values were grouped by LAI (ranging from 1 to 6 , see Table 1 ). The size of a symbol corresponds to its LAI value. 

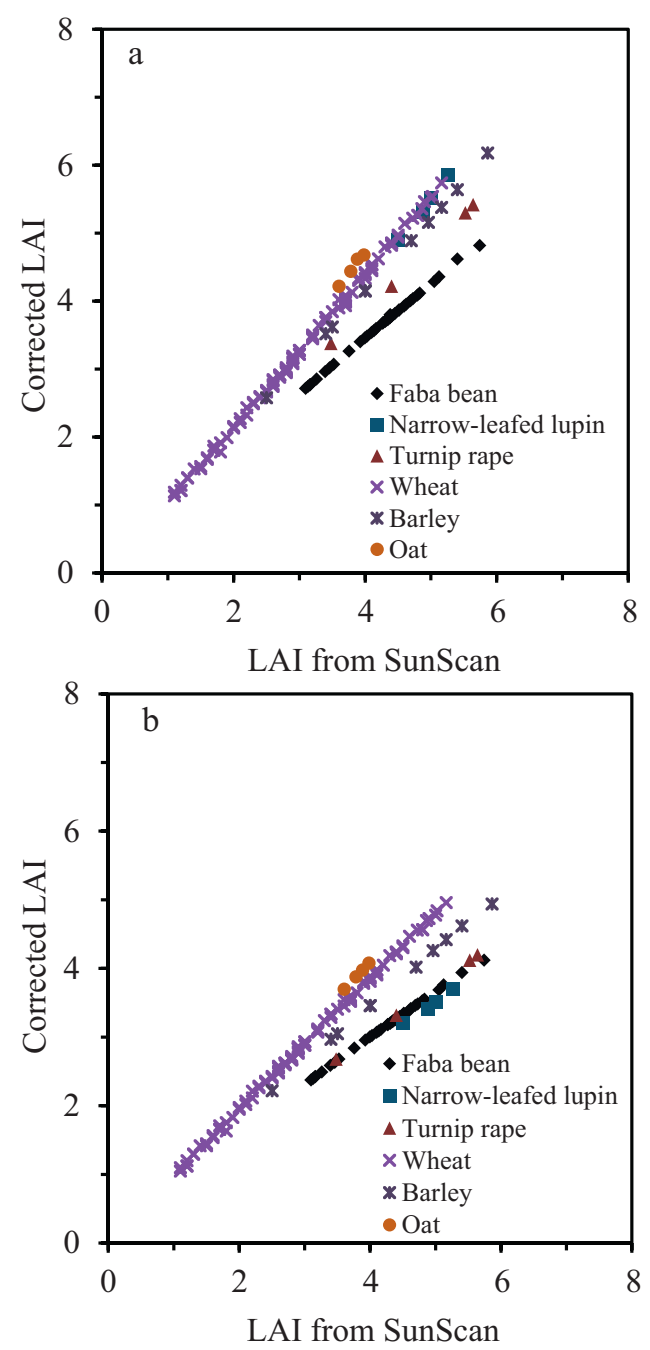

Fig. 9. LAI calculated from SunScan measurements using species-specific leaf angle distribution as a function of LAI estimated using the default settings ( $G \equiv 0.5)$ : (a) SunScan estimate of LAI corrected by LAI-2000 leaf angle measurement and (b) corrected by photographic LAD measurement.

the assumptions underlying the LAI-2000 algorithm are fulfilled, the instrument measures Plant Area Index, or the hemisurface area of all plant elements, and the MTA of all plant elements weighted by their hemisurface areas. One potential reason is that

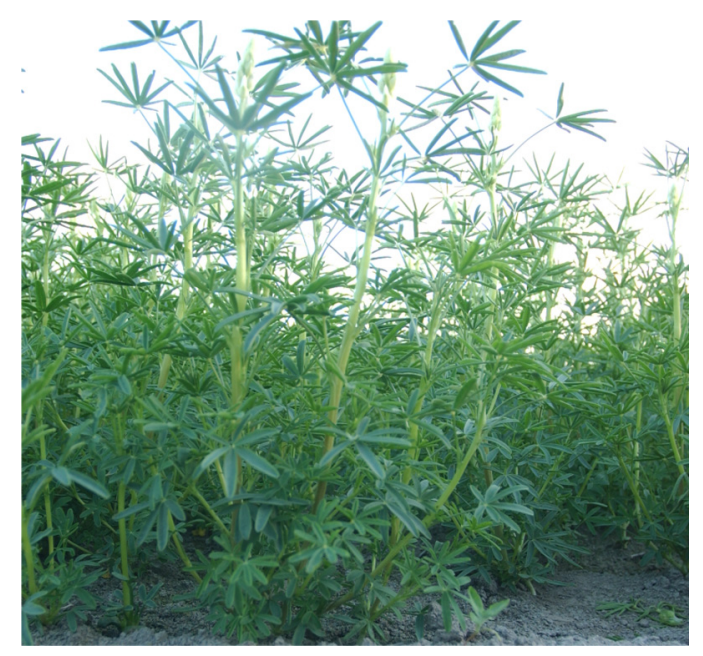

Fig. 10. Narrow-leafed lupin stands in 2012. vegetation structure (clumping) increases canopy transmittance mostly in near-zenith directions (Ryu et al., 2010b), thus distorting the slope of G-function calculated from LAI-2000 measurements. Additionally, gap fraction measurements made even under diffuse sky can include non-ignorable amount of scattered radiation (e.g., Kobayashi et al., 2013) which increases gap fraction measurements. If the gap fraction increases by the same proportion in each ring, this will lead to an overestimation of MTA. However, other angular distributions of diffuse scattering may have an adverse effect on MTA estimation.

It would be expected that the LAI-2000 measured MTA values would correlate better (than photographic MTA) with canopy spectral reflectance as both phenomena are related to how incident radiation interacts with the canopy. Yet, this was not the case for most wavelengths (Fig. 7). This may be a result of MTA variation with height inside the canopy: transmitted radiation is equally influenced by all canopy layers, including the bottom ones containing mostly near-vertical stems. Reflected radiation, on the other hand, mostly interacts with the leafy upper canopy layer, better characterized by the photographic measurement of LAD.

Fig. 7 shows the great potential of determining MTA from singleangle spectroscopic remote sensing data using the spectral region known as the red edge (the region of rapid increase of reflectance with wavelength, between $720 \mathrm{~nm}$ and $776 \mathrm{~nm}$ in our spectral data). However, modeling exercises (e.g., Jacquemoud et al., 2009) have demonstrated that the effects of LAD and LAI on canopy reflectance are very similar and may be difficult to discriminate. Indeed, the spectral dependence of the strength of the measured correlation between MTA and spectral reflectance factor in Fig. 7 strongly resembles the modeled one obtained by Jacquemoud et al. (2009, Fig. 4, the curve for ALA) using PROSAIL: at the long wave end of the red edge part of the spectrum where chlorophyll absorption is small, leaf angle has the largest contribution to crop reflectance. This can be viewed as an indirect validation of the model and we expect that, generally, other modeling results obtained by Jacquemoud et al. (2009) also apply to our measured data. The most important difference between the measured and modeled curve lies in the height and shape of the correlation maximum in the red edge (at $748 \mathrm{~nm}$ ) and the complete lack of correlation in red. Therefore, our data together with other empirical evidence (e.g., Huang et al., 2006) justifies further investigations on the use of these two wavebands for retrieving crop LAD.

An interesting feature found in our data is the strong correlation between the parameter $\mu$ and MTA (Fig. 4). The correlation can be interpreted by analyzing Eq. (3). The first factor determining $\mu,(1-\bar{t})$ is strictly positive and a decreasing function of $\bar{t}$, the MTA value normalized to range between 0 and 1 . Next, if $\bar{t}$ and its standard deviation $\sigma_{t}^{2}$ are strongly correlated (i.e., $\sigma_{t}^{2} \approx k \bar{t}$, the second factor $\left(\sigma_{0}^{2} / \sigma_{t}^{2}\right)-1$ can be rewritten as $\left(\sigma_{0}^{2} / k \bar{t}\right)-1=$ $(1 / k)(1-\bar{t})-1$. Clearly, the last expression is a decreasing linear function of $\bar{t}$. In our measured data, the correlation between $\bar{t}$ and $\sigma_{t}^{2}$ was strong and linear $\left(R^{2}=0.66\right)$ while $\sigma_{t}^{2} / \bar{t}$ was uncorrelated with $\bar{t}\left(R^{2}=0.05\right.$, data not shown here). The true nature of the correlation - why horizontal leaves had smaller variation in their leaf angles compared with canopies of more vertical leaves - and its universality remain to be explored. A similar trend, although considerably weaker, can be seen in the leaf angle data from numerous bushes and trees growing in botanical gardens in Helsinki (unpublished data). Nevertheless, from the 58 deciduous broad-leafed tree species common to temperate and boreal climate (Pisek et al., 2013), $\bar{t}$ and $\sigma_{t}^{2}$ were uncorrelated and, for these species, both $\mu$ and $v$ are required to calculate MTA.

The investigation described here includes only six different crop species measured once during the growing season. However, the results are promising and, in the future, the LADs of other crops can be determined using the photographic method. The photographs 
were taken of the edges of the plots which may affect the measurements in a yet undetermined way. Future studies should analyze the effect of plot edge on leaf angle, existence of preferred leaf azimuth angles, and the contributions of petioles, stems and other plant organs.

\section{Conclusions}

The results of the study confirm that the photographic technique can be used to measure the leaf angle distributions of field crops. Long and curved leaves of crops such as cereals should be divided into segments and the relative contribution of each segment to the final LAD should be determined by its relative area. The high correlation between canopy reflectance in the red edge (at $748 \mathrm{~nm}$ ) and the mean inclination angle of leaves shows a potential for developing a robust algorithm of remote sensing of the leaf inclination angles of field crops.

\section{Acknowledgements}

The research was funded by China Scholarship Council, Centre for International Mobility (CIMO Finland), University of Helsinki Postdoctoral Funds, AISARES doctor program, Marjatta and Eino Kolli Foundation, the Research Foundation of University of Helsinki, Department of Agricultural Sciences of University of Helsinki, the Finnish Cultural Foundation, the MoniPalko project of the Ministry of Agriculture and Forestry of Finland, the EU FP7 project 245216 CP-FP 'Legume Futures: Legume-supported cropping systems for Europe', the FP7-Marie Curie Actions program, and Estonian Science Foundation grants ERMOS32 and PUT232. The authors acknowledge Piia Kekkonen, Jouko Närhi and Markku Tykkyläinen for invaluable technical assistance in the field plots.

\section{References}

Abashina, E.V., Gorbachev, V.A., 1977. Leaf orientation in barley crops. Trans. Inst. Exp. Meteorol. 86, 97-104 (in Russian)

Campbell, G.S., 1986. Extinction coefficients for radiation in plant canopies calculated using an ellipsoidal inclination angle distribution. Agric. For. Meteorol. 36, 317-321.

Campbell, G.S., 1990. Derivation of an angle density function for canopies with ellipsoidal leaf angle distributions. Agric. For. Meteorol. 49, 173-176.

Campbell, G.S., Norman, J.M., 1998. An Introduction to Environmental Biophysics, 2nd ed. Springer, New York.

de Wit, C.T., 1965. Photosynthesis of Leaf Canopies. Agricultural Research Report no. 663, Wageningen

Ehleringer, J.R., Forseth, I.N., 1989. Diurnal leaf movements and productivity in canopies. In: Russell, G., Marshall, B., Jarvis, P.G. (Eds.), Plant Canopies, Their Growth, Form and Function. Cambridge University Press, Cambridge, pp. $129-142$.

Goel, N.S., Strebel, D., 1984. Simple beta distribution representation of leaf orientation in vegetation canopies. Agron. J. 76, 800-802.

Goudriaan, J., 1988. The bare bones of leaf-angle distribution in radiation models for canopy photosynthesis and energy exchange. Agric. For. Meteorol. 43, 155-169.

Gutschick, V.P., 1991. Joining leaf photosynthesis models and canopy photontransport models. In: Myneni, R.G., Ross, J. (Eds.), Photon-Vegetation Interactions. Springer, Berlin, pp. 501-535.

Hosoi, F., Nakai, Y., Omasa, K., 2009. Estimating the leaf inclination angle distribution of the wheat canopy using a portable scanning lidar. J. Agric. Meteorol. 65, 297-302.
Houborg, R., Soegaard, H., Boegh, E., 2007. Combining vegetation index and mode inversion methods for the extraction of key vegetation biophysical parameters using Terra and Aqua MODIS reflectance data. Remote Sens. Environ. 106, 39-58.

Huang, W.J., Niu, Z., Wang, J.H., Liu, L.Y., Zhao, C.J., Liu, Q., 2006. Identifying crop lea angle distribution based on two-temporal and bidirectional canopy reflectance. IEEE Trans. Geosci. Remote Sens. 44, 3601-3609.

Jacquemoud, S., Verhoef, W., Baret, F., Bacour, C., Zarco-Tejada, P.J., Asner, G.P., François, C., Ustin, S.L., 2009. PROSPECT + SAIL models: a review of use for vegetation characterization. Remote Sens. Environ. 113, S56-S66.

Knyazikhin, Y., Schull, M.A., Stenberg, P., Mõttus, M., Rautiainen, M., Yang, Y., Marshak, A., Carmona, P.L., Kaufmann, R.K., Lewis, P., Disney, M.I., Vanderbilt, V., Davis, A.B., Baret, F., Jacquemoud, S., Lyapustin, A., Myneni, R., 2012. Hyperspectral remote sensing of foliar nitrogen content. Proc. Natl. Acad. Sci. U.S.A. 110, 185-192.

Kobayashi, H., Ryu, Y., Baldocchi, D.D., Welles, J.M., Norman, J.M., 2013. On the correct estimation of gap fraction: how to remove scattered radiation in gap fraction measurements? Agric. For. Meteorol. 174-175, 170-183.

Lang, A.R.G., 1986. Leaf area and average leaf angle from transmission of direct sunlight. Aust. J. Bot. 34, 349-355.

Lang, A.R.G., Xiang, Y.Q., Norman, J.M., 1985. Crop structure and the penetration of direct sunlight. Agric. For. Meteorol. 35, 83-101.

Mägi, H., Ross, J., 1969. Photosynthetic characteristics and photosynthetic productivity of a barley stand. II. Growth dynamics of the assimilation area and increase of the dry-matter content. In: Photosynthetic Productivity of a Plant Stand. Institute of Physics and Astronomy, Academy of Sciences of Estonian SSR, Tartu, pp. 143-173 (in Russian).

Nichiporovich, A.A., 1961. On properties of plants as an optical system. Soviet J. Plan Physiol. 8, 536-546 (in Russian).

Pisek, J., Ryu, Y., Alikas, K., 2011. Estimating leaf inclination and G-function from leveled digital camera photography in broadleaf canopies. Trees 25, 919-924.

Pisek, J., Sonnentag, O., Richardson, A.D., Mõttus, M., 2013. Is the spherical leaf inclination angle distribution a valid assumption for temperate and boreal broadleaf tree species? Agric. For. Meteorol. 169, 186-194.

Reynolds, M.P., Ginkel, M., van, Ribaut, J.-M., 2000. Avenues for genetic modification of radiation use efficiency in wheat. J. Exp. Bot. 51, 459-473.

Ross, J., 1981. The Radiation Regime and Architecture of Plant Stands. Dr W. Junk Publishers, The Hague, Netherlands.

Ross, J., Nilson, T., 1965. The extinction of direct radiation in crops. In: Questions on Radiation Regime of Plant Stand. Institute of Physics and Astronomy, Academy of Sciences of Estonian SSR, Tartu, pp. 25-64 (in Russian).

Ross, J., Nilson, T., 1968. Balance of photosynthetically active radiation in plant stands. In: Radiation Regime in Plant Stands. Institute of Physics and Astronomy, Academy of Sciences of Estonian SSR, Tartu, pp. 5-54 (in Russian).

Ryu, Y., Sonnentag, O., Nilson, T., Vargas, R., Kobayashi, H., Wenk, R., Baldocchi, D.D. 2010a. How to quantify tree leaf area index in a heterogeneous savanna ecosystem: a multi-instrument and multi-model approach. Agric. For. Meteorol. 150, 63-76.

Ryu, Y., Nilson, T., Kobayashi, H., Sonnentag, O., Law, B.E., Baldocchi, D.D., 2010b. On the correct estimation of effective leaf area index: does it reveal information on clumping effects? Agric. For. Meteorol. 150, 463-472.

Scott, D., Wells, J.S., 1969. Leaf orientation in barley, lupin, and lucerne stands. N. Zeal. J. Bot. 7, 372-388.

Sinoquet, H., Thalisawanyangkura, S., Mabrouk, H., Kasemsap, P., 1998. Characterization of the light environment in canopies using 3D digitizing and image processing. Ann. Bot. 82, 203-212.

Viña, A., Gitelson, A.A., Nguy-Robertson, A.L., Peng, Y., 2011. Comparison of different vegetation indices for the remote assessment of green leaf area index of crops. Remote Sens. Environ. 115, 3468-3478.

Watson, D.J., 1947. Comparative physiological studies in the growth of field crops. I. Variation in net assimilation rate and leaf area between species and varieties, and within and between years. Ann. Bot. 11, 41-76.

Warren Wilson, J.W., 1967. Stand structure and light penetration. III. Sunlit foliage area. J. Appl. Ecol. 4, 159-165.

Wang, W.M., Li, Z.L., Su, H.B., 2007. Comparison of leaf angle distribution functions: effects on extinction coefficient and fraction of sunlit foliage. Agric. For. Meteorol. 143, 106-122.

Weiss, M., Baret, F., Smith, G.J., Jonckheere, I., Coppin, P., 2004. Review of methods for in situ leaf area index (LAI) determination. Part II. Estimation of LAI, errors and sampling. Agric. For. Meteorol. 121, 37-53.

WRB, 2007. World Reference Base for Soil Resources 2006, first update 2007. World Soil Resources Reports No. 103. FAO, Rome. 